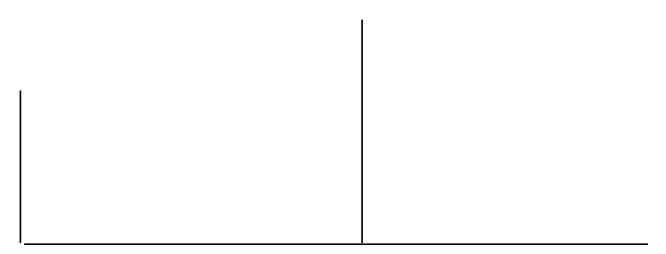

Rev. Latinoam. Psicopat. Fund., VI, 3, 70-82

\title{
Significação e limite da linguagem na formação psicoterapêutica ${ }^{1}$
}

Kimura Bin

\begin{abstract}
As principais escolas de psicoterapias profundas na cultura ocidental têm sua origem na psicanálise freudiana. Apesar das divergências mais ou menos importantes nas teorias e práticas, elas partilham todas um princípio essencial, a saber: que a experiência pode ser verbalizada. Em geral, e principalmente nas culturas ocidentais, experimentar algo significa construir em si uma realidade dada, de modo que ela possa ser verbalmente transmitida ao outro. É somente pela comunicação verbal que a realidade experimentada pode ser partilhada com os outros, comunicando, assim, o domínio intersubjetivo comum. Este artigo examina as diferenças consideráveis nas apreensões culturais da experiência e na maneira da realidade se manifestar, retirando conseqüências apara a atividade psicoterapêutica.
\end{abstract}

Palavras-chave: Psicanálise, comunicação verbal, cultural ocidental

1. Tradução de François Bideaux e Joël Bouderlique, a partir do texto alemão intitulado "Bedeutung der Sprache in der psychotherapeutischen Ausbildung. Tradução para o português, de Monica Seincman. Publicado originalmente em Pierre Fédida et Jacques Schotte (org.). Psychiatrie et existence. Grenoble: Editions Jérôme Millon, 1991, p. 199-212. 
As principais escolas de psicoterapias profundas na cultura ocidental têm sua origem na psicanálise freudiana. Apesar das divergências mais ou menos importantes nas teorias e práticas, elas partilham todas um princípio essencial, a saber: que a experiência pode ser verbalizada. Concretamente, este princípio apresenta os seguintes aspectos:

1. A comunicação verbal recíproca desempenha de longe o papel mais importante, como principal acesso do terapeuta à vida psíquica do paciente. $\mathrm{O}$ terapeuta obtém informações sobre a experiência interior dos pacientes por meio das proposições articuladas verbalmente por estes, respondendo-lhes, por sua vez, comunicandolhes verbalmente também suas interpretações. Mesmo os fenômenos não-verbais, tais como os sonhos, as transferências, as passagens ao ato, podem ser trazidos ao campo da psicoterapia, à medida que podem ser traduzidos em palavras pelo próprio paciente ou pelo terapeuta. Com efeito, pode-se considerar o método clássico de associação livre sobre o divã como um meio de proteção contra os elementos nãoverbais que arriscam sempre, em uma situação de face a face, irromper no plano puramente verbal da comunicação. Finalmente, Jacques Lacan chegou a afirmar que o inconsciente seria estruturado como uma linguagem.

2. No seio do contato entre o mundo interno e o externo, entre a psique e a "realidade", será admitida uma instância "eu" ou "consciente" com capacidade de linguagem. Na psicoterapia ocidental, um "eu" ou um consciente incapaz de se revelar verbalmente seria totalmente impensável. Esta instância falante desempenha o papel do representante para todo o aparelho psíquico e é somente por este viés de sua mediação que o "isso" (Es) ou o "inconsciente" também pode se fazer escutar. Se o objetivo da psicoterapia é reforçar o "eu", isso 


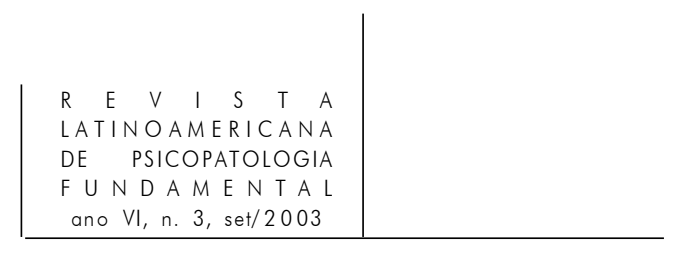

significa simplesmente uma ampliação da capacidade de todo o aparelho psíquico de se articular e se revelar verbalmente. Assim, parece que o paciente será capaz de dominar suficientemente o irracional de seu inconsciente e de colocá-lo sob o controle da razão, somente quando tiver conseguido oferecer-se, em um contexto claramente estruturado e verbalmente comunicável, uma representação interna dos conflitos irracionais ou dos complexos reprimidos nas profundezas de sua vida psíquica, que à primeira vista pareciam ainda muito opacos.

3. Conseqüentemente, a formação psicoterapêutica será também essencialmente determinada por procedimentos verbais e desenvolvida por métodos verbais. Por meio da análise didática, o candidato aprende a fazer, em relação a si mesmo, de seu próprio inconsciente um objeto para verbalizá-lo, e assim construir para o analista didata uma realidade comunicável e, portanto, objetiva. Durante a supervisão, além da comunicação verbal entre o candidato e seu paciente, sua troca emocional não-verbal é também trazida à fala de modo que possa ser controlada e interpretada pelo supervisor por meio da linguagem. Entre outros, o debate versará sobre a questão de saber se o candidato objetiviza corretamente a vida interior do paciente, ou seja, se ele a reconstrói verbalmente com adequação de modo a poder partilhar, como realidade, um mundo comum com seu paciente, mas também com seu supervisor.

Em geral, e principalmente nas culturas ocidentais, experimentar algo significa construir em si uma realidade dada, de modo que ela possa ser verbalmente transmitida ao outro. É somente pela comunicação verbal que a realidade experimentada pode ser partilhada com os outros, comunicando, assim, o domínio intersubjetivo comum. Será compreendida como realidade intersubjetiva comunicável aquela que já, como tal, é recortada pela língua comum, seja ela realmente expressa ou não. Conseqüentemente, há diferenças consideráveis nas apreensões culturais da experiência, ou mesmo na maneira de a realidade se manifestar. Estas apreensões culturais sempre mudam segundo a estrutura da língua falada de região para região, em função da realidade que ela recorta a partir do todo dado. Experimenta-se uma realidade diferente, ao elaborá-la sempre segundo o modelo verbal comum validado e suscitado por sua própria cultura. Por exemplo, em certas culturas o arco-íris tem sete cores, enquanto em outras, somente três, dependendo do número de nomes de que cada uma delas dispõe. Da mesma maneira, a experiência dos laços de fraternidade que tece um japonês é diferente daquela que depende de uma outra língua, pois em japonês não há palavra genérica para "irmão", distinguindo-se, porém, sempre com a palavra ani o irmão mais velho e com a palavra ototo, o mais novo.

Neste mesmo sentido, um psicólogo japonês, Junko Tanaka-Matsumi e seu colaborador americano Anthony Masella (1976) colheram interessantes resultados a partir de uma pesquisa comparativa transcultural sobre a associação de palavras, 


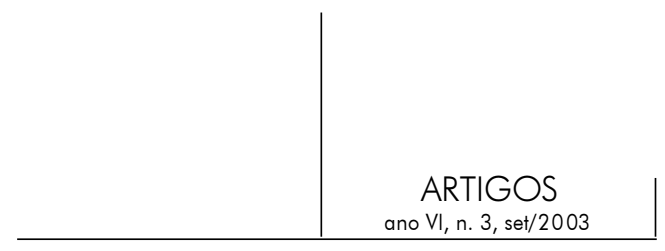

que implicou três grupos étnicos. A saber, um grupo de japoneses autóctones, um de japoneses de língua americana e um de estudantes americanos caucasianos. É preciso observar que os estudantes japoneses de língua americana faziam todos parte da terceira geração de japoneses implantados no Havaí. Foi proposta às pessoas escolhidas em cada grupo a palavra-estímulo "depressão" (Yûutsu para os estudantes que falavam apenas japonês). As associações mais freqüentes apresentadas pelo grupo de japoneses indígenas foram equivalentes, caso traduzíssemos para o português, a: "chuva", "sombra", "preocupação", "cinza", "nebuloso", "suicídio", "solidão", "exames"; as escolhidas pelos japoneses de língua americana foram: "triste", "solitário", "baixo", "frustração", "fraco", "fracasso", "blues", "cansado"; e os americanos caucasianos preferiram: "triste", "isolado", "abatido", "infeliz", “insosso", “deprimido", "hipócrita”, "moroso".

É inicialmente surpreendente observar como a maneira de viver o humor depressivo dos japoneses é próxima da natureza de suas associações com os termos: chuva, obscuridade, nebuloso, etc., enquanto os americanos têm muito mais tendência a ligá-lo a estados intrapsíquicos, tais como tristeza, solidão, abatimento... estando, assim, inclinados a experimentá-lo largamente no plano psicológico. É ainda mais surpreendente ver contrastar nitidamente a concordância absolutamente admirável das associações selecionadas pelos dois grupos de língua americana com as escolhidas pelo grupo que apenas fala japonês. Por outro lado, ao se comparar os dois grupos de japoneses, revelam-se poucas semelhanças. Os japoneses nascidos e educados nos Estados Unidos, e que não mais falavam o japonês, não se comportavam mais como japoneses, mas sim como americanos. Isso corrobora de uma forma convincente o "relativismo lingüístico" ou a hipótese Sapir-Whorf, segundo a qual a língua co-estrutura a realidade.

Isso, retornando ao nosso propósito, faz com que pensemos na estreita relação entre linguagem e experiência das diferentes escolas de psicoterapia, entre aquilo que sobre ela dizem as respectivas teorias e aquilo que, conforme o caso, se constrói como realidade. Sempre acompanhando suas premissas teóricas e as formulações prescritas pela linguagem, as experiências mostram-se diferentes conforme o caso, assim como a realidade parece ser outra em função disso. As formações nas respectivas escolas visam, em primeiro lugar, desenvolver o potencial de experiência do candidato, a fim de que a realidade seja construída de tal forma que seja formulada da melhor maneira possível, segundo sua linguagem teórica. A partir de então, não surpreende que o mesmo sonho de um paciente - experimentado por uma abordagem freudiana ou outra, como a junguiana - possa ser interpretado no sentido de uma realidade completamente diferente. Seria, pois, absurdo, um candidato à psicanálise freudiana querer ser formado por um junguiano. A particularidade de cada psicoterapia ocidental, originando-se na psicanálise, sempre consiste, então, unicamente em seu modo 


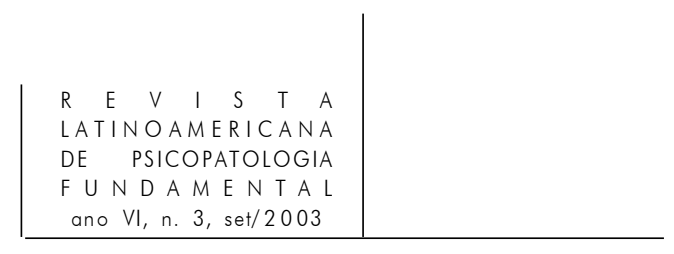

idiossincrático de experiência do psíquico que deve ser colocado em palavras, segundo uma maneira própria a cada uma, de modo que a diferença entre as orientações das diversas escolas possa, em última análise, reduzir-se aos diferentes modos de verbalização.

É precisamente nesta idéia de verbalizabilidade da experiência que o pensamento ocidental, em geral, e a psicoterapia ocidental, em particular, contrastam vivamente com as representações japonesas tradicionais. No Oriente, e particularmente na tradição do Zen budismo, "a experiência pura" (Nishida), ou seja, uma experiência que se localiza aquém e além de qualquer objetivação racional e que é, consequientemente, desprovida de qualquer possibilidade de verbalização real ou potencial, é de uma importância fundamental como lugar autêntico de encontro vivo entre o homem e o mundo; enquanto os esforços do eu articulando e diferenciando conceitualmente as experiências serão considerados uma construção secundária derivada. Kitaro Nishida (1965), o filósofo japonês contemporâneo a Freud e Husserl, cujo pensamento filosófico iniciou-se a partir deste conceito de "experiência pura", diz: "Não é verdade que há, primeiramente, um indivíduo e, em seguida, sua experiência, mas há primeiramente experiência e, em seguida, há indivíduos, cada experiência do indivíduo é apenas um pequeno domínio particular e limitado da experiência pura" (p. 28). Esta frase significa que há, superando a consciência de si de uma individualidade, uma vasta experiência que torna possível, somente a partir de si mesma, algo como sua própria concreção, sua experiência individual separada. Ele denominou tal experiência de "experiência pura". Ela se compreende, conseqüentemente, como lugar em que uma certa realidade originária é experimentada sob um modo imediato, antes de qualquer construção verbal de realidades particulares e antes de qualquer consciência de si de um eu individual, sem mediação como tal. Os japoneses pensam que esta realidade originária deve declinar sua imediatidade, a partir do momento em que é levada à fala. É por isso que, neste mesmo sentido, a formação no Zen budismo será, quanto ao essencial, efetuada segundo o preceito do Furyuh-monji (sem dirigir a palavra), e do Kyoghe-betsuden (transmitir fora do ensinamento).

No Zen budismo, os sábios que leram muito e que são versados em todos os tipos de teorias, em vez de serem venerados, serão, às vezes, desprezados. Os ensinamentos escritos são simplesmente considerados inúteis. Certamente os koan, estes enigmas que os mestres Zen dão a seus discípulos para interpretarem a fim de testar seu satori, são no entanto formulados verbalmente. Mas são apenas paradoxos que devem unicamente servir, por meio da própria linguagem, para destruir sua função racional de comunicação. Assim, por exemplo, será ordenado encontrar o lugar autêntico do ser de si onde os próprios pais nem eram ainda nascidos, ou ainda se afirma que a quintessência do budismo é o carvalho que 


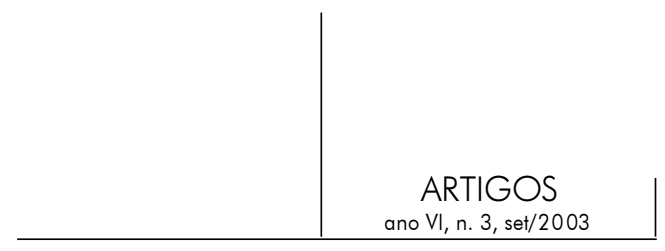

se encontra no jardim. Por meio de tais fórmulas contraditórias, a realidade nãoverbalizável deve ser atingida imediatamente sem desvio pela linguagem. Mas, para atingir tal iluminação, é necessária uma longa preparação. O satori somente se produz após longos anos de relação pessoal com o mestre que sabe comunicar esta realidade originária a seus alunos não pela linguagem teórica, mas em uma relação de coração a coração na partilha de uma vida cotidiana.

No diálogo psicoterapêutico, recolhemos informações sobre o paciente por vias verbais e não-verbais, e, ao mesmo tempo, nós mesmos produzimos sobre ele efeitos por meios igualmente verbais e não-verbais. O processo global da psicoterapia é, assim, tecido de um entrelaçamento extremamente complexo de input e output, que em caso algum devem ser compreendidos como funções em si mesmas autônomas, independentes umas das outras. Não é que, de um lado, dirijamos nossa atenção terapêutica para o paciente e que, de outro, registremos objetivamente seus estados. Na psicoterapia, as observações serão constantemente muito mais efetuadas com os "olhos" das ações terapêuticas como tais; em outras palavras, por uma ação singular do sentido terapêutico, um sensorium que toma para si as finas regulações da situação global. Se, por exemplo, no diálogo com o paciente, queremos conhecer seu posicionamento interior em relação ao ambiente e a si mesmo - em si mesma dificilmente verbalizável -, não podemos nos satisfazer com suas respostas às nossas questões ao longo de alguns diálogos, mas devemos nos esforçar para o abordar muito lentamente por uma relação terapêutica que pode se estender, às vezes, por anos. Estas abordagens terapêuticas atuantes como tais funcionam como o órgão das observações. Além da representação dualista de uma ação ativa oposta à observação passiva, devemos conceber uma unidade inseparável do agir e do perceber, um tipo de Gestaltkreis (círculo da forma), conforme colocado por Viktor von Weizsäcker.

Esta capacidade cognitiva da ação prática é apreendida por Nishida (1965a, p. 541) pelo termo “intuição no ato" (Ko' iteki chokkan). Ele diz: "Agir é ver", o exemplo mais convincente é, a seu ver, a comunidade de ação da produção e da percepção no ato criador do artista. A fim de compreender isso mais concretamente, lembraremos a experiência da escuta que pertence necessariamente ao ato de execução musical. Assim podemos executar uma música sem, ao mesmo tempo, escutar os sons e as melodias tocadas por nós mesmos. Quando diversos músicos tocam juntos um trecho de música de câmera, a escuta simultânea, não apenas de sua própria parte, mas também do trecho em sua totalidade, revela-se indispensável. Não podemos dizer que seguimos passo a passo nossa produção musical de ouvido. Executar e escutar pertencem juntos a uma exata simultaneidade. O ato de tocar, como tal, está, por assim dizer, continuamente se percebendo a si mesmo. No entanto, esta percepção não é em 


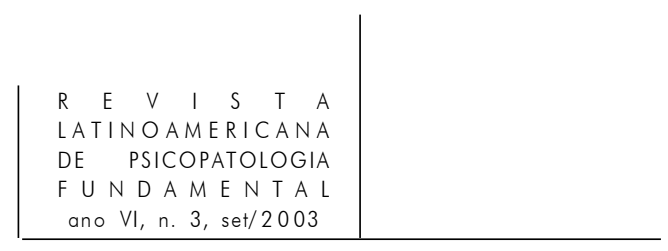

si e por si objetivante; ela não oferece objeto algum à experiência. Antes de qualquer coisa, nem mesmo observamos que no ato percebemos também, ao mesmo tempo, que isso viria somente depois por meio de uma reflexão subseqüente. "O experimentado" por meio da intuição no ato pertence, pois, essencialmente à "experiência pura" não-objetivável e não-verbalizável.

$\mathrm{O}$ termo japonês que corresponde aos termos portugueses linguagem ou palavra, ou aos termos alemães Sprache ou Wort, é kotoba. Etimologicamente isso significa uma partícula superficial $(b a)$ da realidade $(k o t o)$. Vemos, aí, um aspecto essencial do modo de pensar tradicional japonês, segundo o qual a língua ou a palavra não podem apresentar nada além do que a superfície da realidade. Daí vem também a profunda desconfiança já evocada do Zen budismo em relação às palavras. Isto se deve a um contraste preciso com o pensamento ocidental, sobretudo o pensamento cristão, que pode dizer: "no começo era logos e o logos estava com Deus e Deus era o logos". O que parece caracterizar tanto o conjunto da cultura ocidental, quanto suas teorias psicoterapêuticas é justamente este "logocentrismo". Em contrapartida, no Oriente, não se pode dizer que o logos (kotoba) era o princípio, pois deve a cada vez ser recortado do koto para representar verbalmente suas sombras superficiais. No princípio, pois, há o koto, a realidade.

Koto é próxima a uma outra palavrinha, mono, que também está entre os termos mais freqüentemente utilizados na língua japonesa atual; sem elas nenhuma comunicação sensata seria possível. Enquanto na língua japonesa de hoje $m o n o^{1}$ corresponde bastante bem à palavra alemã Ding ou Sache, ou à palavra portuguesa coisa ou objeto, é muito mais difícil encontrar um equivalente qualquer para koto nas línguas européias. Um dicionário japonês-alemão de uso corrente oferece assim mais de vinte palavras como equivalentes possíveis. Encabeçando a lista, encontramos Ding e Sache, em português coisa e objeto, exatamente como para a tradução de mono, depois segue uma série de palavras variadas; em alemão: Angelegenheit, Ereignis, Begebenheit, Tatsache, Umstand, Verhältnis, Geschäft, Arbeit, Erfahrung, Frage, Problem, Gerücht, Unfall, Zwischenfall, Unglück, Streit, Zwist, Fall und Grund. A tradução para o português dá: evento, acontecimento, incidente, fato, circunstância, relação ou relacionamento, comerciar com, trabalho, experiência, pergunta, problema, rumor, acidente, infelicidade, querela, discórdia, caso e fundo ou fundamento. Mesmo nesta longa enumeração alguns sinônimos importantes faltam, tais como, por exemplo:

1. No japonês antigo, a palavra mono também era utilizada como eufemismo expressando o aterrorizante ou o inquietante. 


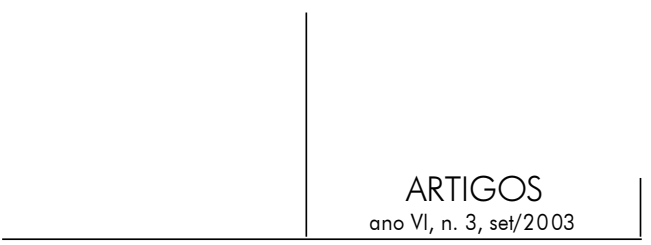

Wirklichkeit, Sachverhalt em alemão (realidade e estado de coisa, em português) e, enfim, a conjunção $d a \beta$ em alemão, que em português.

Conseqüentemente, mono significa na qualidade de coisa ou na de objeto algo que é ou aquele que é isto ou aquilo, ou seja, significa o sendo em geral (Seiendes), em contrapartida, koto significa primeiramente o fato, a realidade, o estado de coisa (Sachverhalt), que algo é isso ou aquilo, que algo se conduz desta ou daquela maneira, que algo tem este ou aquele caráter. Por exemplo, a mesa e a sala aqui pertencem a mono, assim como o tema de minha conferência, a cidade de Cerisy, sua beleza, sua distância do Japão, etc. Este conceito visa, portanto, sempre alguma coisa objetivável, que se pode encontrar como objeto, quer ele seja real, concreto ou ideal, uma abstração, e se deixe, conseqüentemente, sempre representar por um substantivo. Por outro lado, este fato ou esta realidade devem sempre ser consideradas como koto, por exemplo: aqui nesta sala, encontra-se uma mesa, nós nos encontramos em Cerisy e discutimos o tema da formação, a cidade é bela e se encontra muito longe do Japão, etc. Assim, koto será em geral traduzido por uma frase ou por uma proposição subordinada introduzida pela conjunção que, contendo um verbo (Zeitwort) e se reportando, dessa maneira, a uma experiência no mínimo potencialmente verbalizável e cuja afirmação vem de um sujeito. Conseqüentemente, pode-se dizer que mono assume seu lugar em um espaço real ou ideal, enquanto koto não ocupa espaço, mas tempo, que ele se temporaliza (Sich zeitigen) na experiência de um sujeito. Mono é representado como o sendo (Seiendes) que é um sendo real ou imaginário, independente da experiência de um sujeito, enquanto a sobrevinda da situação de koto requer sempre a participação do sujeito que a experimenta. Apesar de estes dois termos terem em comum a mesma significação: "coisa" ou "objeto", entre eles reside uma diferença que não pode ser ignorada. Fala-se de mono caso se queira dizer uma coisa ou um objeto em seu estar-sob-a-mão (Vorhandenheit) objetivo fora da vida subjetiva, enquanto se fala de koto quando se trata de designá-los em sua realidade subjetiva ou intersubjetiva na vida.

No entanto, o horizonte de sentido do conceito koto não se limita de forma alguma a este único aspecto. Em japonês, tem-se também uma outra palavra koto que com efeito significa fala ou palavra. Apesar de, atualmente, ela ser escrita com um ideograma diferente daquele que se utiliza para significar a "realidade", em seu sentido originário não pode ser separada do primeiro koto mencionado. O japonês antigo, antes da incorporação dos ideogramas chineses, e o que parece muito importante, antes da introdução do budismo, ignorava ainda a diferença entre os fatos experimentados de uma situação (koto como realidade) e suas enunciações (koto como fala). Segundo um dicionário de japonês antigo (Ohno e Maeda, 1974, p. 499), na antiguidade japonesa, uma palavra pronunciada significava simplesmente a realidade que ela expressava e acreditava-se também 


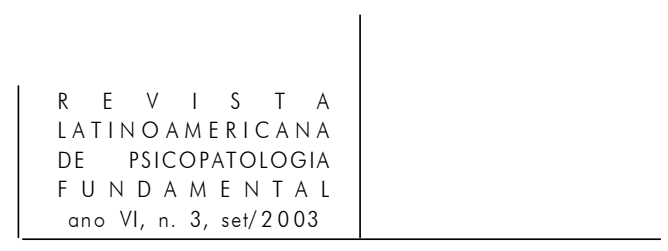

no inverso, que uma realidade imediata podia ser apreendida pelas palavras. Por isso, palavra e realidade não eram separadas conceitualmente, uma e outra eram compreendidas unicamente por meio da palavra koto. Somente mais tarde, a partir da era de Nara (século VIII), que se começa, talvez sob a influência crescente do budismo que se impõe cada vez mais nessa época, a separá-las cada vez mais nitidamente e assim nomear koto, no sentido da "palavra" kotoba. Nesta, começou-se a reconhecer somente uma faceta superficial e ainda mais facilmente descritiva da realidade em si não-racionalizável. No entanto, a antiga coesão das duas significações conserva ainda hoje uma certa validade.

Destas discussões etimológicas complicadas sobre mono, koto e kotoba, advém que há dois níveis diferentes de experiência da realidade. Um deles se refere a esta realidade, da qual somente a superfície será representada verbalmente, que tende, em sua essência, além de qualquer verbalizabilidade e se torna acessível unicamente na "experiência pura" ou na "intuição no ato". O outro, pelo contrário, refere-se a estas realidades isoladas que coincidem completamente com o campo do poder da fala ou da palavra ou que estão mesmo sempre já verbalmente estruturadas. Nestes últimos casos, deparamo-nos com estas realidades que dependem completamente das compreensões linguageiras terminológicas respectivas do mundo que variam, assim, sempre segundo a cultura, como o mostra a enquete transcultural conduzida por Tanaka-Matsumi e Marsella. As realidades que as escolas de psicoterapias ocidentais crêem atingir por seus métodos idiossincráticos de conceituação pertencem certamente também a este último nível.

O homem é um Zoon logon echon, um animal racional, um ser vivo dotado de fala. Ele não tem somente a ver com o mundo como totalidade do mono, mas o compreende simultaneamente como a totalidade do koto ou, para retomar Heidegger, como o "conjunto referencial" (Bewandnisganze), que significa experimentar o mundo como um contexto sempre já recortado na previsão de seu inventário lingüístico. Apesar de o homem se distinguir por sua capacidade de fala, ele é, no entanto, como qualquer ser vivo, um ser capturado com seu poder-viver enquanto vive. O homem não é apenas uma máquina falante. A capacidade que tem de representar para si verbalmente seu mundo de vida está também fundada no fato último de que tem de viver sua vida, de que, como ser vivo, tem relação com seu mundo de vida e deve nele tomar posição.

Este fato irracional e oculto da vida que o homem, somente por meio de seu agir prático, pode abrir à sua vida, está na base de cada relação do homem com seu mundo objetal. Não está apenas na base, mas as ativa constantemente ou mesmo as coloca em movimento. Em qualquer experiência, o homem não se situa somente em face de seu objeto respectivo, mas também, ao mesmo tempo, 


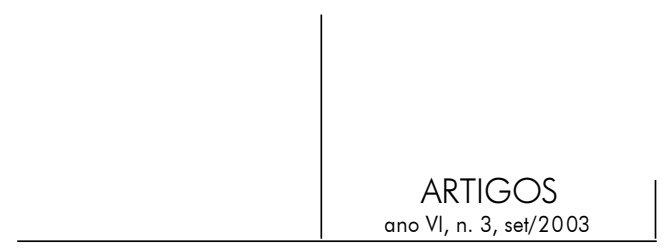

deste fato fundamental da própria vida. Esta dupla estrutura da relação humana com a realidade corresponde ao duplo sentido de koto anteriormente evocado. Por um lado, no sentido da realidade além da verbalizabilidade, e, por outro, no sentido da realidade sempre já construída verbalmente. A fim de assegurar o em direção a que (wozu) de sua relação com o mundo, o homem se refere, por um lado, para isso, a uma experiência racional objetivante do mundo dos objetos e, de outro, mais simultaneamente, à "intuição no ato" irracional instintivo do fundo oculto da vida.

Isso também é válido para a experiência do "ser-si" e do "ser-com-osoutros" da qual, finalmente, toda a psiquiatria e toda psicoterapia estão de posse. Tanto a experiência do "ser-si" no sentido "relacionar-se-consigo-mesmo" quanto a do "ser-com-os-outros" no sentido de "relacionar-se-com-seus-semelhantes" acompanham sempre esta "intuição no ato" do fato fundador da vida. Qualquer situação neurótica e psicótica pode, inicialmente, ser compreendida como distúrbios da relação consigo mesmo e com os outros. Estes distúrbios, por sua vez, devem ser referidos à história de uma falha da relação com aqueles que são próximos repetida desde o nascimento. Falei sobre este fenômeno detalhadamente em um outro contexto (Kimura, 1975, 1983), nomeando-o "acontecimento do ser-entre".

$\mathrm{O}$ entre, de que aqui se trata, corresponde à palavra japonesa aïda e significa não apenas o entre no sentido de Martin Buber (1954), mas também o "ser-si" simplesmente tal como Kierkegaard (1956) pôde formulá-lo: "uma relação que se relaciona consigo mesmo”. Segundo Kierkegaard, esta relação, quando é proposta por um outro, é novamente uma relação que se relaciona com este outro. O que entendia o filósofo dinamarquês por "outro" era certamente o Cristo como encarnação do paradoxo de ser ao mesmo tempo o Deus infinito e o homem finito. No entanto, em nosso contexto, poderíamos compreender este outro como o fundo inobjetivável e irracional da vida. Com efeito, a relação que, em nome do si, relaciona-se consigo mesmo é constituída como propriedade particular por meio do fundo da vida. Assim sendo, o Si como relação consigo mesmo é também ao mesmo tempo a relação com o fundo da vida. Para nós, trata-se então, em qualquer distúrbio neurótico ou psicótico do acontecimento da ä̈da, do entre como relação irracional com a relação consigo, e ao mesmo tempo com o fundo irracional da vida que sempre estabeleceu a relação completa.

Considerando-se o que acabou de ser dito, a história individual da relação consigo e da relação com os outros deverá ser sempre acompanhada pela relação com o fundo da vida. $\mathrm{O}$ dito inconsciente ou dimensão de profundidade da psique não consiste apenas na história da experiência de si mesmo e dos outros que foi conscientemente vivida e, em seguida, ocultada, mas simultaneamente na história das experiências com este fundo da vida que, por natureza, permanece no não- 


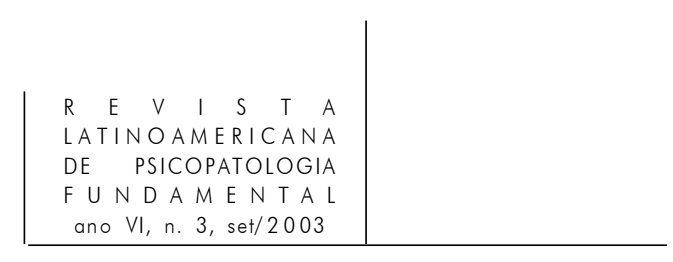

verbal; uma história da experiência pura somente acessível pelo sensorium da intuição no ato, sobre a qual Nishida pôde dizer que precede cada experiência individual separada e que somente ela a torna possível como limitação sua.

Conseqüentemente, a tarefa da psicoterapia consiste em uma tentativa de construção de um aïda terapêutico, que deve exercer uma ação sobre a vida psíquica do paciente de modo a que este possa, doravante, relacionar-se de uma maneira menos perturbada consigo mesmo e com os outros. Esta tarefa só poderá se realizar se o terapeuta, por meio de sua própria relação com o fundo da vida, participar terapeuticamente na de seu paciente. Trata-se aí de uma participação que corresponde, no verdadeiro sentido do termo, à Einfühlung (empatia). É somente por tal Einfühlung de um aïda comum, de um entre comum na relação com o fundo da vida, que um verdadeiro encontro entre terapeuta e paciente se torna possível e que o paciente, com o apoio deste aïda, pode novamente instaurar uma relação mais sadia com a realidade.

A tarefa da psicoterapia não se reduz, portanto, a ordenar em um nível verbalizável a relação do paciente consigo mesmo e com os outros. Certamente, qualquer psicoterapia profunda se esforçará também por interrogar a relação inconsciente ainda não verbalizada consigo e com os outros, de modo a modificar, assim, a influência desta dimensão de profundidade nas relações conscientes consigo mesmo e com os outros. Mas, para isso, deve-se primeiramente verbalizar o inconsciente e torná-lo abordável racionalmente. Isso se passa geralmente por meio da mobilização das formulações teóricas disponíveis. No entanto, por meio de tal verbalização subseqüente na língua teórica, o acontecimento na dimensão profunda perde necessariamente sua verdadeira profundidade. Conseqüentemente, a dimensão profunda será objetivada, presa nas redes da linguagem teórica e separada da autêntica instância que efetua o fundo da vida, e isso sem interrogar se é possível verbalizá-lo corretamente. Não se pode mais esperar que um "fundo" assim racionalizado seja uma instância que constantemente proponha e entretenha a relação consigo e com o outro.

Com certeza, em qualquer psicoterapia, sempre se vê uma Einfühlung que age terapeuticamente, enquanto uma relação viva médico-paciente for mantida, independentemente do modo segundo o qual esta relação teórica se deixe interpretar. Uma relação terapêutica de longa duração com uma implicação humana suficiente deve sempre, independentemente da forma de sua verbalização, exercer uma influência restabelecedora sobre a relação do paciente com sua vida, que pode certamente levar também a uma melhora desejável de sua relação consigo mesmo e com os outros. No entanto, não devemos nos iludir sobre esta melhora, reduzindo-a ao resultado de um trabalho terapêutico sobre a relação do paciente com a realidade traduzida em linguagem teórica. Devemos, quanto a isso, sempre estar prontos para fazer face a uma questão irônica, a saber, se esta melhora foi 


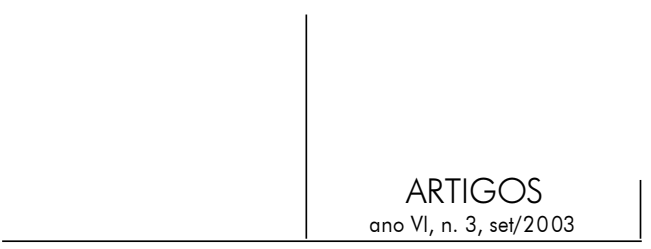

realmente causada pela psicoterapia ou se ela simplesmente não veio durante, e mesmo, apesar da psicoterapia.

Conseqüentemente, o que importa efetivamente na formação dos psicoterapeutas é como esta Einfühlung terapêutica, esta relação terapêutica nãoverbalizável com o fundo da vida do candidato, pode ser transmitida. Sem dúvida, devemos, antes de tudo, cuidar sempre de novamente mostrarmos claramente ao candidato que todas as teorias são somente precárias tentativas de verbalização da dimensão profunda da experiência humana, colocando-se além de qualquer fala, e que uma verdadeira e salvadora comunicação com o paciente só pode acontecer na dimensão irracional ou pré-racional do ä̈da. Isso implica sempre que as pretensões de validade de suas próprias teorias ou conceitos devem ser relativizadas ou suspensas. No Zen budismo, há uma sentença que diz: "Quando vir o mesmo, mate-o". Há, com certeza, poucos discípulos que irão assim mais longe do que o mestre em seu satori. Mas na psicoterapia, igualmente, é por meio de alguns alunos geniais que foram fundadas as novas etapas de compreensão. O que se pode obter de uma formação apenas por meio da linguagem teórica nada mais é senão uma reprodução em massa de uma multidão de psicoterapeutas medianos, por mais importante que em si isso possa ser. Um verdadeiro desenvolvimento da psicoterapia não poderá se dar senão por alguns discípulos que não recuam, tremendo, diante do assassinato do mestre.

\section{Referências}

Buber, M. Die Schriften über das dialogische Prinzip. Heidelberg, 1954.

KierkegaArd, S. Die Krankheit Zum Tode und anderes. Hegner: Köln und Olten, 1956.

KIMURA, B. Schizophrenie als Geschehen des Zwischenseins. Nervenarzt 48, 434-9, 1975.

La spacialité intersubjective et la schizophrénie. In: PÉLICIER, Y. Espace et psychopathologie. Paris: Economica, 1983.

NishidA, K. Zen no kenkyu (Études sur le Bien). In: Oeuvres complètes I. Tóquio: Iwanami Shoten, 1965.

Ko'iteki Chokkan (Contemplation agissante). In: Oeuvres complètes VIII. Tóquio: Iwanami Shoten, 1965a.

Ohno, S., Satake, A. e Maeda, K. Iwanami Kogo Jiten. Tóquio: Iwanami Shoten, 1974.

Tanaka-Matsumi, J., Marsella, A.J. Cross-cultural variations in the phenomenological experience of depression I, World association studies. Journal of Cross-Cultural Psychology, 7, p. 379, 1976. 


\section{Resumos}

Las principales escuelas de psicoterapia profunda en la cultura occidental tienen su origen en el psicoanálisis freudiano. A pesar de las divergencias, más o menos importantes en las teorías y prácticas, comparten todas un principio esencial: la experiencia puede ser verbalizada. En general, y principalmente en las culturas occidentales, experimentar algo significa construir en sí una realidad dada, de modo que ella pueda ser verbalmente transmitida al otro. Es sólo por la comunicación verbal que la realidad experimentada puede ser compartida con los otros, comunicando así, el dominio ínter subjetivo común. Este artículo examina las diferencias considerables en las aprehensiones culturales de la experiencia y en la manera de la realidad manifestarse, retirando consecuencias para la actividad psicoterapéutica.

Palabras claves: Psicoanálisis, comunicación verbal, cultura occidental

Les principales écoles de psychothérapie profonde de la culture occidentale trouvent leur origine dans la psychanalyse freudienne. Malgré les divergences théoriques et pratiques plus ou moins importantes, elles partagent un principe essentiel, à savoir : que l'expérience peut être verbalisée. En général, et principalement dans les cultures occidentales, expérimenter quelque chose signifie construire en soi une réalité donnée, de sorte qu'elle puisse être transmisse à l'autre verbalement. C'est seulement par la communication verbale que la réalité vécue peut être partagée avec les autres, en communiquant ainsi le domaine intersubjectif commun. Cet article examine les différences considérables des appréhensions culturelles de l'expérience et de la manière dont la réalité se manifeste, ayant des conséquences sur l'activité psychothérapeutique.

Mots clés: Psychanalyse, communication verbale, culture occidentale

The most important schools of depth psychotherapies in Western culture have their origin in Freudian psychoanalysis. Despite more or less important disagreements as to theory and practice, they all share an essential principle, namely, that experience can be verbalized. In general, and especially in Western cultures, to experience something means to construct a given reality within oneself in such a way that it can be verbally expressed to the other. It is only through verbal communication that experienced reality can be shared with others, thus communicating the common intersubjective domain. This article examines the considerable differences in the cultural apprehension of experience and in the way that reality is manifest, and presents conclusions for psychotherapeutic work.

Key words: Psychoanalysis, communication verbal cultural, Western

Versão inicial recebida em dezembro de 2002

Aprovado para publicação em julho de 2003 